By Olga Izryadnova

\title{
Real Economy: Trends and Factors
}

In Q3 2012 the GDP growth rates slowed down to 2.8\% versus 3.9\% in Q2 and 4.9\% in Q1 2012. In September 2012 as compared with September 2011 investments in fixed assets contracted by 1.3\% and workload in construction - by 5.6\%. In September 2012 for the first time in the post-crisis period growth rates in machine-building were observed to be below the average for manufacturing production and for the industry as a whole. Economic growth rates slowing down, acceleration of growth rates of the real incomes of the population by $3.8 \%$ and of the real wages - by 6.6\% versus September 2011 contributes to the trend of the production costs increase due to the growth of labor remuneration costs and leads to the worsening of enterprises' operation results. The decrease of the general unemployment to the level that is the minimum for ten-year period can be characterized as a plus.

According to the estimations of the RF Ministry of Economic Development, in JanuarySeptember 2012 as compared with the corresponding period of the previous year the GDP growth rates made 103.8\%. In Q3 2012 the GDP growth rates slowed down to 2.8\% versus 3.9\% in Q2 and 4.9\% in Q1 2012. The slowdown of the GDP growth rates in Q3 2012 is connected with the structural characteristics of the economic growth.

Table 1

Main Macroeconomic Indices in 2011-2012, as Percentage to the Corresponding Period of the Preceding Year

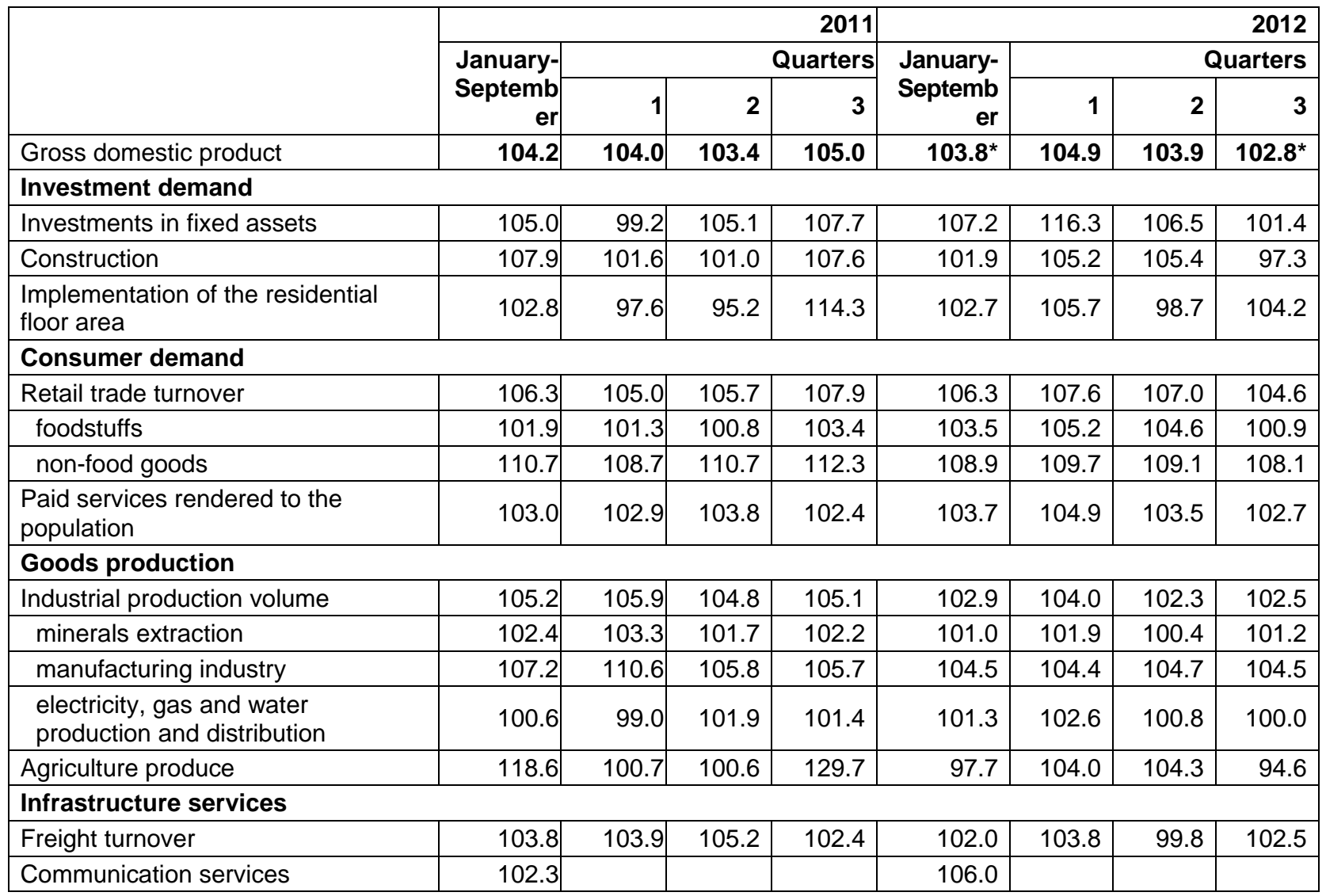




\begin{tabular}{|c|c|c|c|c|c|c|c|c|}
\hline & \multicolumn{4}{|c|}{2011} & \multicolumn{4}{|r|}{2012} \\
\hline & \multirow{2}{*}{$\begin{array}{r}\text { January- } \\
\text { Septemb } \\
\text { er }\end{array}$} & \multicolumn{3}{|c|}{ Quarters } & \multirow{2}{*}{$\begin{array}{r}\text { January- } \\
\text { Septemb } \\
\text { er }\end{array}$} & \multicolumn{3}{|c|}{ Quarters } \\
\hline & & 1 & 2 & 3 & & 1 & 2 & 3 \\
\hline \multicolumn{9}{|l|}{ Social parameters } \\
\hline Real disposable monetary incomes & 100.1 & 100.2 & 98.7 & 101.4 & 103.6 & 102.4 & 104.0 & 104.3 \\
\hline Real wages & 102.6 & 101.6 & 102.7 & 103.8 & 109.4 & 110.3 & 111.3 & 106.9 \\
\hline Real volume of accrued pensions & 100.9 & 102.7 & 99.4 & 100.6 & & 104.4 & 106.8 & \\
\hline \multicolumn{9}{|l|}{ Labor market } \\
\hline Total number of the unemployed & 88.3 & 85.7 & 88.1 & 91.8 & 85.3 & 86.7 & 84.8 & 84.4 \\
\hline $\begin{array}{l}\text { Number of officially registered } \\
\text { unemployed }\end{array}$ & 75.3 & 73.1 & 75.4 & 78.0 & 79.5 & 80.1 & 78.5 & 79.9 \\
\hline \multicolumn{9}{|l|}{ External factors } \\
\hline Foreign trade turnover & 133.0 & 129.3 & 139.4 & 130.0 & $103.4^{*}$ & 114.9 & 98.1 & $99.4^{*}$ \\
\hline export & 131.4 & 122.8 & 137.3 & 133.7 & $103.7^{*}$ & 116.5 & 98.3 & $97.9^{\star}$ \\
\hline import & 135.6 & 142.5 & 142.6 & 124.7 & $103.2^{*}$ & 112.1 & 97.8 & $101.4^{*}$ \\
\hline
\end{tabular}

*) preliminary data

Source: RF Ministry of Economic Development, Federal State Statistics Service

This year the investment and consumer demand are characterized by the decaying wave dynamics (table 1). The upsurge of the investment activity in H1 2012 was interrupted in JulySeptember 2012. In Q3 2012 investment in fixed assets exceeded the figure off the corresponding period of the previous year by only 1.4\% (16.6\% in Q1 and 8.5\% in Q2 2012) and were insufficient to maintain the positive dynamics of workload in construction and regularity of residential floor area implementation. Although on the whole in January-September 2012 the indices of investment activity went up, when estimating the situation one should take into account that in September 2012 the investments in fixed assets decreased by 2.3\%, workload in construction - by $5.6 \%$ and implementation of the residential floor area - by $7.2 \%$ versus September 2011. The RF Ministry of Economic Development estimated the growth rates of the investments in fixed assets to be at the level of 102.6\% in H2 2012 versus the corresponding period of the previous year. As a result the increase in the investments in fixed assets in 2012 will make $5.5 \%$ versus $8.3 \%$ a year ago.

The growth of the consumer demand in January-September 2012 remained one of the main factors supporting the economic dynamics. However, quarter-by-quarter dynamics of the retail trade turnover in the current year reveals gradual diminishing of the demand growth rates for both the foodstuffs and the non-food goods. In January-September 2012 the growth rates of the retail trade turnover made $106.3 \%$ and were equal to the figure of the corresponding period of the previous year. The incomes of the population increasing, such dynamics can be accounted for by the change in the consumer behavior: in Q3 2012 the trend towards the proportion of expenses for foreign currency purchase was observed to expand while the proportion of savings and expenses for goods and services purchase was contracting.

Consumer prices index made 105.2\% from the beginning of the year to September 2012 as compared with $104.7 \%$ in the corresponding period of 2011 , the prices for the foodstuffs at the same time went up by $4.8 \%$ ( $0.8 \%$ in 2011$)$, for non-food goods - by $3.7 \%(5.0 \%)$ and for paid services - by $6.7 \%$ (8.1\%). 
The dynamics of the industrial production was considerably influenced by the changes in the price situation at the domestic market. In September 2012 the index of producer prices for industrial goods made $104.8 \%$ (109.4\% for the period from the beginning of the year), being $115.9 \%$ (131.7\%) in mineral extraction, $101.3 \%$ (104.2\%) in manufacturing industry, $101.6 \%$ (107.2\%) in electricity, gas and water production and distribution. In September 2012 the growth of prices in fossil fuels extraction was mainly caused by the increase of prices for crude oil by $25.7 \%$, and in manufacturing industries - by the increase in prices for coke and oil products production by $5.5 \%$. In spite of the fuel and electricity becoming more expensive manufacturing industries still stick to the policy of the reserved growth of prices. It is the foodstuffs production that is the exception due to the growth of prices for the raw materials as a result of the recession in agricultural production.

In January-September 2012 the index of the industrial production was equal to $102.9 \%$ (105.2\% a year ago), being $101.0 \%$ (102.4\%) in minerals extraction, $104.5 \%$ (107.2\%) in manufacturing industry. At the same time in September 20122 the volumes of the mineral extraction and manufacturing production were observed to decrease as compared with August 2012 by $1.5 \%$ and $1.2 \%$, correspondingly.

In January-September 2012 the index of fossil fuels extraction made 101.4\% versus the corresponding period of 2011, oil extraction volume being $385.6 \mathrm{~m}$ tons exceeding by $1.0 \%$ the corresponding figure of 2011, natural gas extraction volume being $476.4 \mathrm{bn} \mathrm{cu} \mathrm{m}(97.0 \%$ of the figure of 2011). In January-September 2012 the Russian oil refineries received 200.6m tons of crude oil for processing (104.2\% versus the corresponding period of 2011) and $178.5 \mathrm{~m}$ tons (99.3\%) was directed to export. The proportion of the oil processing in the total volume of oil extraction went up to $52.0 \%$ in January-September 2012 as compared with $50.4 \%$ in the corresponding period of 2011. Oil products production index in January-September 2012 as compared with the corresponding period of 2011 made 102.4\%, in September 2012 the growth rates of the volume of the primary oil processing making 105.1\% versus September 2011.

According to the live data of the RF Ministry of Energy, in January-September 2012 as compared with January-September 2011 the consumption of the natural gas in the domestic market went down by $1.7 \%$ and its export - by $6.0 \%$.

In August and September of the current year the manufacturing industry was characterized by the decrease in the output versus the preceding month, which determined monthly negative dynamics of the industrial production on the whole over Q3 2012.

Since in the post-crisis period dynamic recovery of the machine-building industry had a considerable effect on the aggregated figure of the manufacturing industries development, it should be noted that this year a sharp slowdown of the growth rates in all types of machinebuilding industries was observed. In September the registered growth rates for machine-building industries have been the lowest for the elapsed period of 2012. This month as compared with the corresponding period of 2011 the index of the machinery and equipment production made 89.5\% (100.4\% in January-September), of the electric, electronic and optical equipment production $100.3 \%$ (105.2\%), of the transport vehicles and equipment production $-100.0 \%$ (117.2\%). The positive dynamics in transport vehicles and equipment production is still maintained due to 
passenger cars production which compensates for the decrease in trucks and some types of railway equipment production.

The investment activity and demand for the capital goods growth rates slowing down, the production of the construction materials, construction and metallurgy products is still characterized by anticipating growth rates, the machinery and equipment stocks growing simultaneously. The comparison of the dynamics of the main indices of the investment market reflects the delay in the producers' reaction to the changes in the situation with the internal demand and can later result in considerable changes in the output plans for the production adjacent with the construction complex.

In September 2012 the majority of the intermediate goods productions were observed to decrease the output considerably as compared with the previous month: chemistry industry - by $5.7 \%-8.0 \%$ depending on the type of activity, in timber industry - by $3.4 \%-7.3 \%$. The slowdown of the growth rates versus September 2011 and decrease in the production as compared with the previous month reflects both the internal limitations in the development of particular enterprises (production facilities, staff reserves) and the change in the demand for the production at the internal and external markets.

Out of the industries producing consumer demand goods it if only the foodstuffs production that is characterized by the steady positive dynamics at the moment. Textile and sewing industry, as well as production of leather, leather goods and footwear are contracting as compared with the previous year. However analyzing the dynamics of the foodstuffs production, one should take into account the impact of the agriculture production. The decrease in the agriculture produce output has resulted in the systematic slowdown of the foodstuffs production throughout 2012. In September 2012 the agriculture production volume made 92.3\% versus the corresponding figure of 2011 (97.7\% over January-September), and foodstuffs output - 103.6\% (105.6\%).

Taking into account the existing trends of Q2 and Q3 2012, it seem difficult to reach the growth of industry of $103.6 \%$ this year declared in the RF Ministry of Economic Development forecast.

The current year is specifically characterized by the intensive growth of the real income of the population and real wages against the background of the steady slowdown of the economic growth rates. On the whole in January-September of the current year the real incomes went up by $3.6 \%$, real wages - by $9.4 \%$ as compared with the corresponding period of the previous year. In September 2012 the growth of the real disposable incomes made 103.8\% versus the figure of the previous year and the growth of real wages $-106.6 \%$. The anticipating growth of real wages versus labor efficiency results in the increase of the production costs and worsening of the financial and economic result of enterprises' operation. The proportion of the gross profit in the GDP in H1 2012 made 26.2\% and was 1.7\% below the corresponding figure of 2011.

It should also be noted that the situation at the labor market is exceptional for the past ten years - the level of the unemployment (as calculated by ILO methodology) is at the lowest and made $5.2 \%$ of the total number of the economically active population in September 2012. For a year the demand for the workforce from the employers as declared to the state employment 
agencies has been observed to grow as compared with the previous year. As at the end of September 2012 the job bank contained information about $1.57 \mathrm{~m}$ of vacant positions while only $1.02 \mathrm{~m}$ of the unemployed was registered in the unemployment agencies. The tension coefficient decreased due to the contraction of the number of the registered unemployed and made 74 per 100 declared vacant positions as at the end of September 2012 as compared with 98.8 a year ago. 